\title{
Prospective cohort study reveals MMP-9, a neuroplasticity regulator, as a prediction marker of cochlear implantation outcome in prelingual deafness treatment
}

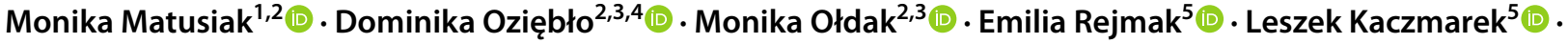 \\ Piotr Henryk Skarżyński ${ }^{6,7,8}$ (D) . Henryk Skarżyński ${ }^{1,2}$ (D)
}

Received: 31 May 2021 / Accepted: 4 January 2022 / Published online: 21 January 2022

(c) The Author(s) 2022

\begin{abstract}
Because of vast variability of cochlear implantation outcomes in prelingual deafness treatment, identification of good and poor performers remains a challenging task. To address this issue, we investigated genetic variants of matrix metalloproteinase $9(M M P 9)$ and brain-derived neurotrophic factor $(B D N F)$ and plasma levels of MMP-9, BDNF, and pro-BDNF that have all been implicated in neuroplasticity after sensory deprivation in the auditory pathway. We recruited a cohort of prelingually deaf children, all implanted before the age of 2 , and carried out a prospective observation $(N=61)$. Next, we analyzed the association between (i) functional MMP9 (rs20544, rs3918242, rs2234681) and BDNF (rs6265) gene variants (and their respective protein levels) and (ii) the child's auditory development as measured with the LittlEARS Questionnaire (LEAQ) before cochlear implant (CI) activation and at 8 and 18 months post-CI activation. Statistical analyses revealed that the plasma level of MMP-9 measured at implantation in prelingually deaf children was significantly correlated with the LEAQ score 18 months after CI activation. In the subgroup of DFNB1-related deafness $(N=40)$, rs3918242 of $M M P 9$ was significantly associated with LEAQ score at 18 months after CI activation; also, according to a multiple regression model, the ratio of plasma levels of pro-BDNF/BDNF measured at implantation was a significant predictor of overall LEAQ score at follow-up. In the subgroup with DFNB1-related deafness, who had CI activation after 1 year old $(N=22)$, a multiple regression model showed that rs3918242 of $M M P 9$ was a significant predictor of overall LEAQ score at follow-up.
\end{abstract}

Keywords Neuronal plasticity $\cdot$ Congenital deafness $\cdot$ Cochlear implantation $\cdot$ MMP-9

Monika Matusiak and Dominika Oziębło contributed equally

to this work.

Monika Matusiak

m.matusiak@ifps.org.pl

1 Oto-Rhino-Laryngosurgery Clinic, Institute of Physiology and Pathology of Hearing, 10 Mochnackiego Street, 02-042 Warsaw, Poland

2 World Hearing Centre, 17 Mokra Street, 05-830, Nadarzyn, Poland

3 Department of Genetics, Institute of Physiology and Pathology of Hearing, 10 Mochnackiego Street, 02-042 Warsaw, Poland

4 Postgraduate School of Molecular Medicine, Medical University of Warsaw, 61 Żwirki i Wigury Street, 02-091 Warsaw, Poland
5 BRAINCITY, Nencki Institute of Experimental Biology, 3 Pasteura Street, 02-093 Warsaw, Poland

6 Department of Teleaudiology and Screening, World Hearing Center, Institute of Physiology and Pathology of Hearing, 10 Mochnackiego Street, 02-042 Warsaw, Poland

7 Heart Failure and Cardiac Rehabilitation Department, 2Nd Faculty of Medicine, Medical University of Warsaw, 8 Kondratowicza Street, 03-242, Warsaw, Poland

8 Institute of Sensory Organs, 1 Mokra Street, 05-830, Nadarzyn/Kajetany, Poland 


\section{Introduction}

\section{Congenital Deafness Treatment with Cochlear Implantation and Variability of Its Outcome}

Congenital deafness is a disabling condition which, untreated, has far-reaching consequences and profoundly affects the quality of the patient's life. Cochlear implants (CIs) and neuroprostheses commonly used in treating the disease are a very effective tool for restoring absent auditory function. However, despite the undeniable success of the method, one caveat is a large degree of variability in outcomes across individual CI users. Beside the very good performers, who develop speech and language almost normally, some implanted children, despite great effort at rehabilitation, never reach age-appropriate proficiency in speech, language, and verbal communication [1-3]. For clinicians, it is difficult to preoperatively predict how well an individual patient will perform with a CI. Only a part of the variance in performance can be accounted for by known factors, such as age of implantation, etiology of hearing loss, existence of comorbidities, and others [1-12].

Genetic causes of hearing loss are heterogeneous, and there are ethnic-specific differences in the involvement of particular genes in its development. In the majority of countries, mutations in the GJB2 and GJB6 genes (DFNB1 locus) are the leading cause of hearing loss, and they are identified in up to $50 \%$ of patients with severe-to-profound autosomal recessive nonsyndromic deafness [13]. The presence of pathogenic variants in the DFNB1 locus causes malfunctioning of the organ of Corti, although the molecular mechanism behind it is still under investigation $[14,15]$. Delivery of electrical stimulation to the auditory pathway involves an interplay between implant software and brain tissue (wetware) [1, 4]. For this reason, it is thought that the missing factors contributing to CI outcome, which might also serve as either biochemical or genetic biomarkers of auditory development following a CI, could be located in the biological environment of the implant [4]. Finding such biomarkers would be important, as it would allow increased efforts to be made in identifying children at risk of failure of their CI.

\section{Neuronal Plasticity}

The cerebral cortex of a developing child responds to sensory stimuli coming from the child's environment by undergoing neuronal plasticity $[1,16]$. The ability to modify the strength and efficacy of cortical synapses is the neurons' essential attribute and is needed for learning and memory, but in an aberrant form it contributes to many pathological conditions such as addiction, schizophrenia, or epilepsy [1, 17-19]. The recent introduction of the tetrapartite synapse concept has drawn attention to the extracellular matrix (ECM) as a factor contributing to synapse function and dysfunction [17]. The ECM might be cleaved by matrix metalloproteinases (MMPs), making it particularly susceptible to remodeling processes [17, 18, 20-23]. MMPs are a family of metzincin proteinases with an established role in developmental plasticity -well documented in the case of MMP-9 [20, 21]. Experimental data demonstrate that MMP-9 is a critical factor in latephase long-term potentiation (LTP), which is considered the physiological basis of synaptic plasticity [24-27]. It has also been postulated, based on research on rodent models, that MMP-9 is involved in plasticity during critical periods in development by regulating synaptogenesis, axonal growth, and myelination [20]. Furthermore, genetic association studies have supported the role of MMP-9 in a series of brain disorders involving aberrant plasticity [17, $19,28]$. BDNF is another protein of pivotal importance in neuronal plasticity $[29,30]$. The molecule can potentiate synaptic transmission, thus inducing LTP, and is tightly connected with cognitive processes, memory, and learning [29, 31, 32]. Interestingly, the protein might be cleaved from pro-BDNF into a mature BDNF form (BDNF) by MMP-9 [29, 32-36].

Given the reported role of both MMP-9 and BDNF in neuronal plasticity, it may be beneficial to study their roles in auditory plasticity after a child with congenital deafness receives a CI. For this reason, we have designed an association study between polymorphisms known to affect $M M P 9$ and $B D N F$ expression and auditory development as measured by the LEAQ score. The study was performed in a group of deaf infants and toddlers implanted with the same type of device. We have also searched for associations among plasma levels of MMP-9, BDNF collected at cochlear implantation, and pro-BDNF/BDNF ratio and the children's auditory development.

\section{Aim of the Study}

In this study, we wanted to test the hypothesis that carrying a specific set of functional $M M P 9$ and $B D N F$ gene variants, and protein plasma levels of MMP-9, BDNF, and pro$\mathrm{BDNF} / \mathrm{BDNF}$ ratio, measured at cochlear implantation, can serve as prognostic biomarkers of functional outcomes of CI treatment in a population of congenitally deaf children. To verify this assumption, we collected a dataset from a cohort of 70 implanted infants and toddlers. To our knowledge, the role of $M M P 9$ and $B D N F$ genes together with their proteins in the neuroplasticity of the human auditory system has not been explored so far. 


\section{Material and Methods}

\section{Study Design, Participants, and Ethical Approval}

This prospective cohort study was done between December 2016 and December 2019 in the Institute of Physiology and Pathology of Hearing in Warsaw, Poland. We recruited infants and toddlers with hearing loss, who underwent cochlear implantation with the same type of device, performed by the same surgeon, and who all had their speech processor activated before the age of 2 . Inclusion criteria were congenital bilateral profound sensorineural hearing loss, confirmed by auditory brainstem responses (ABR). Exclusion criteria were the presence of any acute inflammation confirmed by CRP (C-reactive protein) measurements and the presence of environmental risk factors, such as chronic concomitant disease, severe prematurity, asphyxia, or history of viral infection during pregnancy. After activation of the CI, parents or caregivers followed instructions of auditory-verbal therapy. Children were clinically assessed for auditory development by using the LEAQ before CI activation and at the $8^{\text {th }}$ and $18^{\text {th }}$ month after CI activation (LEAQ_0, LEAQ_8, LEAQ_18). Additionally, at cochlear implantation patients had their blood sampled for genetic polymorphisms testing and MMP-9, BDNF, pro-BDNF, and CRP plasma level (MMP-9_0, BDNF_0, pro-BDNF_0). Out of 70 children enrolled in the study, one patient was excluded due to autism spectrum disorder diagnosed during follow-up (and therefore assessed as having unreliable auditory development); two cases were excluded due to the parents withdrawing from the study; and six patients were excluded due to elevated CRP levels. LEAQ scores were successfully collected from all participants at all three intervals. Demographic data were also obtained. Participants underwent genetic testing of the DFNB1 locus and were classified into two subgroups: DFNB1related deafness and not DFNB1-related deafness. Following the line of maximal homogeneity, patients with DFNB1-related deafness were divided into subgroups according to their age at CI activation: "CI activation before 1 year old" and "CI activation after 1 year old".

\section{Auditory Development Assessment}

Participants were assessed for their auditory development by the LEAQ, which is designed for very young children [37]. LEAQ consists of 35 questions with a "yes" or "no" answer. The total score is the number of "yes" answers. The LEAQ has been validated in over 20 languages [38-43].

\section{Polymorphism Selection and Genotyping}

Genotyping of functional variants of $M M P 9$ and $B D N F$ was included to the study protocol. We selected variants that exert a documented effect on gene expression and were associated with different clinical conditions.

The rs3918242 and rs2234681 polymorphisms are situated in the $M M P 9$ gene promoter and may affect its expression [17, 19, 22, 28]. The rs3918242 of MMP9 gene has been found to be associated with depression and schizophrenia, with the $\mathrm{C}$ allele increasing the susceptibility risk to these disorders, and the $\mathrm{T}$ allele, on the other hand reducing the risk $[17,28]$. The rs 2234681 , a microsatellite repeat of (CA)n, is a multiallelic polymorphism. The length of the CA repeat is closely related to $M M P 9$ transcriptional activity. It increases the binding affinity of the transcription factor(s) with the MMP9 promoter [44-46]. This polymorphism has been associated with cardiac and kidney problems [47, 48]. The rs20544 is located in the 3'UTR of MMP9 and is strongly associated with the severity of a chronic delusional syndrome in schizophrenia patients [49]. The rs6265 of $B D N F$ gene results in a valine-to-methionine substitution (Val66Met), leading to reduced $B D N F$ expression. This polymorphism has been widely implicated in a variety of psychiatric disorders such as unipolar and bipolar disorder, depression, and anxiety [30].

The MMP9 polymorphism rs3918242 (NM_004994.2:c.$1590 \mathrm{C}>\mathrm{T}$ ) was genotyped using the PCR-RFLP method. The genomic region encompassing rs3918242 was amplified using forward 5'-GCCTGGCACATAGTAGGCCC-3' and reverse 5'-CTTCCTAGCCAGCCGGCATC-3' primers (Oligo IBB PAN, Warsaw, Poland), and the PCR product was digested with the PaeI restriction enzyme (Thermo Fisher Scientific, Waltham, MA, USA). The allele containing reference variant $C$ was represented by a DNA band of size $435 \mathrm{bp}$, and the allele containing alternative variant $\mathrm{T}$ was represented by bands of sizes 188 and $247 \mathrm{bp}$.

Genotyping of $M M P 9$ polymorphism rs2234681 (13-26 CA repeats around NM_004994.2:c.-90) included amplification with forward 5'-FAM-CTGAGGGCCTGCGGTTTC CT3' and reverse 5'CCTTGACAGGCAAGTGCTGACT3' primers (Oligo IBB PAN). PCR products were separated by capillary electrophoresis on a 3500xL Genetic Analyzer (Applied Biosystems, Foster City, CA, USA). Results were analyzed with GeneMapper v4.1 software (Applied Biosystems) and reported as either less than $20 \mathrm{CA}$ repeats $(<20)$ or equal to or more than $20 \mathrm{CA}$ repeats $(\geq 20)$.

The MMP9 polymorphism rs20544 (NM_004994.2:c.*3C $>\mathrm{T}$ ) and the BDNF polymorphism rs6265 (NM_170735.5:c.196G > A) were genotyped using predesigned TaqMan SNP genotyping assays (Applied Biosystems) and a real-time PCR system (Viia7, Thermo Fisher Scientific). 
The accuracy of genotyping was confirmed by Sanger sequencing in randomly selected samples. The results were $100 \%$ concordant. Detailed genotyping conditions are available upon request.

\section{Plasma Sample Collection}

Blood samples were collected on heparin and centrifuged at $1400 \mathrm{~g}$ for $15 \mathrm{~min}$. Next, plasma was obtained, aliquoted, and stored at $-80^{\circ} \mathrm{C}$ for further analysis. Total protein content was measured with a BCA protein assay kit (ThermoScientific) following the manufacturer's protocol.

\section{MMP-9, BDNF, and pro-BDNF Plasma Level Measurements}

Plasma concentrations of MMP-9, BDNF, and pro-BDNF were determined by ELISA (MMP-9 and BDNF - R\&D Systems Inc., Minneapolis, USA; pro-BDNF - Aviscera Bioscience, Santa Clara, CA, USA) according to the manufacturer's protocol. A total of $30 \mu \mathrm{g} / \mu \mathrm{l}$ of protein from each plasma sample was diluted 70-fold (MMP-9) or 20-fold (BDNF and pro-BDNF) with calibration diluent from the assays and analyzed in duplicate. The optical density of wells was measured at $450 \mathrm{~nm}$ using an automated microplate reader (Sunrise Microplate Absorbance Reader).

\section{Statistical Analyses}

\section{Paired Comparisons Methodology}

For all tested follow-up intervals (i.e., at the time of CI activation, and at the $8^{\text {th }}$ and $18^{\text {th }}$ month after CI activation), comparisons of mean LEAQ scores, BDNF levels, and MMP-9 levels were made between patients with different genotypes using a Welch two-sample $t$-test (if test assumptions were met) or the Wilcoxon rank-sum test. All calculations were performed with $\mathrm{R}$ (version 3.6.3). Results were considered statistically significant at a $p$-value $\leq 0.05$.

\section{Correlation Analysis Methodology}

LEAQ scores measured at different time intervals from CI activation and BDNF, MMP-9 levels, and pro-BDNF/BDNF ratios measured at $\mathrm{CI}$ activation were tested for correlation and strength using a Pearson test (if test assumptions were met) or a Spearman test. Prior to correlation tests, a Shapiro-Wilk test of normality was made in order to check assumptions. All variables for which the correlation was tested were normalized using the min-max scaling method. Correlations were considered statistically significant at $p$-value $\leq 0.05$. All computations were made using $\mathrm{R}$ version 3.6.3 (2020).

\section{Modelling Methodology}

To address the longitudinal aspect of the study design, linear mixed-effect models were built. BDNF, MMP-9, and pro-BDNF/BDNF ratio levels, as well as $B D N F$ rs6265, $M M P 9$ rs3918242, MMP9 rs20544, and MMP9 rs2234681 genotypes, sex, follow-up interval, and age at CI activation were included in the models as a set of predictors. Differences were considered statistically significant at $p \leq 0.05$. All calculations were performed with $\mathrm{R}$ (version 3.6.3) and lme 4, blme, stargazer, and lmerTest packages. Further details about the methodology can be found in our previous publication [44].

\section{Results}

\section{Sample Demographics and Auditory Development}

In the group of 61 implanted children, $28(45.9 \%)$ were girls and 33 boys (54.1\%). In 24 children (39.3\%) some responses at or over $80 \mathrm{~dB}$ on $\mathrm{ABR}$ were recorded, while in 37 children (60.7\%) there were no responses on ABR. The mean age at $\mathrm{CI}$ activation in the study group was 411.4 days $(\min =208 ; \max =739 ; \mathrm{SD}=135.1)$. In 40 cases, DFNB 1related deafness was identified. In this subgroup, 18 (45\%) were girls and 22 were boys (55\%). In 14 children (35.0\%), some responses on $\mathrm{ABR}$ at or over $80 \mathrm{~dB}$ were recorded, while in 26 children $(65.0 \%)$ there were no responses on $\mathrm{ABR}$. The mean age at $\mathrm{CI}$ activation in the subgroup was 407.7 days $(\min =208, \max =654, \mathrm{SD}=128)$. All children were implanted with the Med-El Synchrony CI and became regular CI users. All participants were of Caucasian origin.

\section{Genotyping}

Distributions of genotypes were in the Hardy-Weinberg equilibrium in the whole studied cohort. For rs3918242 of $M M P 9$ gene, the $\mathrm{C} / \mathrm{C}$ genotype was found in 43 cases (70.49\%) and the $\mathrm{C} / \mathrm{T}$ genotype in 18 cases $(29.51 \%)$. For rs20544 of $M M P 9$ gene, the $\mathrm{C} / \mathrm{C}$ genotype was found in 16 cases $(26.23 \%)$, the $\mathrm{C} / \mathrm{T}$ genotype in 29 cases $(47.54 \%)$, and the T/T genotype in $16(26.23 \%)$ cases. For rs2234681 of $M M P 9$ gene, the $<20 /<20$ genotype was found in 17 cases (27.87\%), the $<20 \geq 20$ genotype in 34 cases $(55.74 \%)$, and the $\geq 20 / \geq 20$ genotype in 10 cases (16.39\%). For rs6265 of $B D N F$ gene, the Val/Met genotype was found in 18 cases (29.51\%) and the $\mathrm{Val} / \mathrm{Val}$ genotype in 43 cases $(70.49 \%)$. Allele frequencies of the tested variants did not differ statistically from those reported in population databases (Supplementary Table 1). 


\section{MMP-9, BDNF, and pro-BDNF Plasma Levels}

The mean value of protein plasma level of MMP-9_0 was $236.94 \mathrm{ng} / \mathrm{ml}$, and the levels varied from 31.14 to 769.67 (SD 135.59). Mean value of protein plasma level of BDNF_0 was $2.28 \mathrm{ng} / \mathrm{ml}$, the levels varied from 0.25 to 12.17 (SD 1.91). Mean value of protein plasma level of pro-BDNF_0 was 19.31, and the levels varied from 0.00 to 162.16 (SD 36.08). Mean value of pro-BDNF_0/ BDNF_0 ratio was 15.02, and the values varied from 0.00 to 161.55 (SD 31.64).

\section{Analyses in the Study Group}

In the study group, no significant associations between $M M P 9$ and $B D N F$ genetic variants and LEAQ score at any of the tested follow-up intervals (before $\mathrm{CI}$ activation, and at the $8^{\text {th }}$ and $18^{\text {th }}$ month after CI) were identified (data not shown). No significant associations were identified between pre-CI ABR results and LEAQ score at any of the tested follow-up intervals, as well as between pre-CI ABR results and $M M P 9$ and $B D N F$ genetic variants (data not shown).

We did not observe any significant correlations of the protein levels of MMP-9_0, BDNF_0, and pro-BDNF_0/ BDNF_0 ratio with LEAQ_0 and LEAQ_8. Testing correlations between MMP-9_0, BDNF_0, and pro-BDNF_0/ BDNF_0 ratio with LEAQ_18 showed a weak negative correlation between MMP-9_0 and LEAQ_18 score $(p<0.05$, rho $=-0.25)$ (Fig. 1).
Analyses in the Subgroup with DFNB1-Related Deafness

In the subgroup with DFNB1-related deafness, we identified a significant association between rs3918242 MMP9 and LEAQ 18 . No statistically significant associations were seen for the other tested polymorphisms at any of the follow-up intervals (Table 1). No significant associations were identified between pre-CI ABR results and LEAQ score at any of the tested follow-up intervals, as well as between pre-CI $\mathrm{ABR}$ results and $M M P 9$ and $B D N F$ genetic variants (data not shown).

There was no correlation between plasma levels of MMP-9_0 and BDNF_0 and pro-BDNF_0/BDNF_0 ratio with LEAQ_0 and LEAQ_8 in the DFNB1-related deafness subgroup.

A weak negative correlation was found between plasma levels of MMP-9_0 with LEAQ_18 in the DFNB1-related deafness subgroup $(p<0.01$, rho $=-0.4)$ (Fig. 2). There was no correlation between BDNF_0 and pro-BDNF_0 / BDNF_0 ratio and LEAQ_18.

To build a linear mixed-effect model using plasma levels of the analyzed proteins as predictors for the subgroup with DFNB1-related deafness, observations for every patient were broken down into single measurements of language development (LEAQ score) from CI activation to the $18^{\text {th }}$ month after $\mathrm{CI}$ activation. This gave a set of 120 observations. The model revealed that, apart from the follow-up interval, the pro-BDNF_0/BDNF_0 ratio is a significant predictor of auditory development. The average $R^{2}$ for the model was 0.72 , indicating that it could explain a considerable level of
Fig. 1 Correlation between plasma levels of MMP-9_0 and auditory development measurements at the $18^{\text {th }}$ month after CI activation (LEAQ_18) in the study group

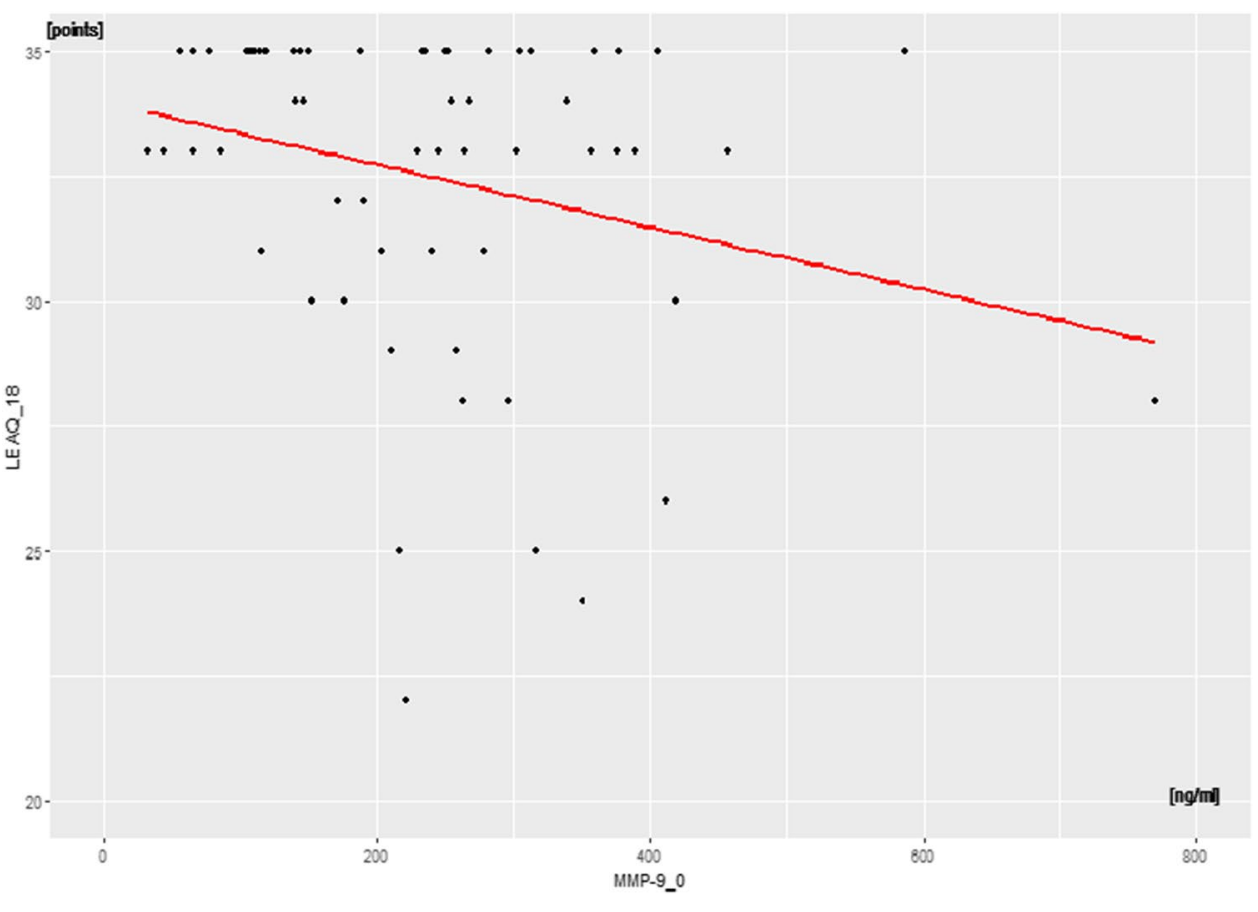


Table 1 Association of auditory development measures (LEAQ score) with $M M P 9$ and $B D N F$ variants in all tested intervals in the subgroup with DFNB1related deafness $(N=40)$. * indicates $p<0.05$

\begin{tabular}{|c|c|c|c|}
\hline & Follow-up interval & Mean LEAQ score (SD) & $p$-value \\
\hline \multicolumn{4}{|l|}{$M M P 9$ rs3918242 } \\
\hline $\mathrm{C} / \mathrm{C}(30) \mathrm{C} / \mathrm{T}(10)$ & 0 & $6.5(7.1) / 2.5(3.9)$ & 0.06 \\
\hline $\mathrm{C} / \mathrm{C}(30) \mathrm{C} / \mathrm{T}(10)$ & 8 & $27.8(4.6) / 25.3(8.3)$ & 0.5 \\
\hline $\mathrm{C} / \mathrm{C}(30) \mathrm{C} / \mathrm{T}(10)$ & 18 & $33.2(2.7) / 30.6(3.9)$ & $0.03^{*}$ \\
\hline \multicolumn{4}{|l|}{$M M P 9$ rs2234681 } \\
\hline$<20 /<20(11) \geq 20 / \geq 20(6)$ & 0 & $7.1(9) / 7.3(8)$ & 0.7 \\
\hline$<20 /<20(11) \geq 20 / \geq 20(6)$ & 8 & $29.5(3.4) / 25.8(6.2)$ & 0.2 \\
\hline$<20 /<20(11) \geq 20 / \geq 20(6)$ & 18 & $33(2.9) / 31.7$ (4.4) & 0.7 \\
\hline$<20 /<20(11)<20 / \geq 20$ & 0 & $7.1(9) / 4.3(4.9)$ & 0.4 \\
\hline$<20 /<20(11)<20 / \geq 20$ & 8 & $29.5(3.4) / 26.4(6.4)$ & 0.2 \\
\hline$<20 /<20(11)<20 / \geq 20$ & 18 & $33(2.9) / 32.6(3.1)$ & 1.0 \\
\hline$<20 / \geq 20(23) \geq 20 / \geq 20(6)$ & 0 & $4.3(4.9) / 7.3(8)$ & 0.2 \\
\hline$<20 / \geq 20(23) \geq 20 / \geq 20(6)$ & 8 & $26.4(6.4) / 25.8(6.2)$ & 0.8 \\
\hline$<20 / \geq 20(23) \geq 20 / \geq 20(6)$ & 18 & $32.6(3.1) / 31.7(4.4)$ & 0.8 \\
\hline \multicolumn{4}{|l|}{$M M P 9$ rs20544 } \\
\hline $\mathrm{C} / \mathrm{T}(21) \mathrm{T} / \mathrm{T}(11)$ & 0 & $4.7(4.9) / 8.5(9.1)$ & 0.3 \\
\hline $\mathrm{C} / \mathrm{T}(21) \mathrm{T} / \mathrm{T}(11)$ & 8 & $26.5(6.2) / 29.6(3.4)$ & 0.4 \\
\hline $\mathrm{C} / \mathrm{T}(21) \mathrm{T} / \mathrm{T}(11)$ & 18 & $32.62(3.1) / 33.3(2.9)$ & 0.3 \\
\hline $\mathrm{C} / \mathrm{C}(8) \mathrm{T} / \mathrm{T}(11)$ & 0 & $3.6(6.3) / 8.5(9.1)$ & 0.2 \\
\hline $\mathrm{C} / \mathrm{C}(8) \mathrm{T} / \mathrm{T}(11)$ & 8 & $25.6(6.7) / 29.6(3.4)$ & 0.1 \\
\hline $\mathrm{C} / \mathrm{C}(8) \mathrm{T} / \mathrm{T}(11)$ & 18 & $32.5(3.1) / 33.3(2.9)$ & 1.0 \\
\hline $\mathrm{C} / \mathrm{C}(8) \mathrm{C} / \mathrm{T}(21)$ & 0 & $3.6(6.3) / 4.7(4.9)$ & 0.6 \\
\hline $\mathrm{C} / \mathrm{C}(8) \mathrm{C} / \mathrm{T}(21)$ & 8 & $25.6(6.7) / 26.5(6.2)$ & 0.7 \\
\hline $\mathrm{C} / \mathrm{C}(8) \mathrm{C} / \mathrm{T}(21)$ & 18 & $32.5(4) / 32.2(3.1)$ & 0.4 \\
\hline \multicolumn{4}{|l|}{$B D N F$ rs6265 } \\
\hline Val/Val (29) Val/Met (11) & 0 & $4.4(5.4) / 8.4(9)$ & 0.1 \\
\hline Val/Val (29) Val/Met (11) & 8 & $27.1(5) / 27.4(7.7)$ & 0.4 \\
\hline Val/Val (29) Val/Met (11) & 18 & $32.7(3) / 32.2(3.7)$ & 0.8 \\
\hline
\end{tabular}

Fig. 2 Correlation between MMP-9_0 plasma level and LEAQ score at the $18^{\text {th }}$ month after CI-activation (LEAQ_18) in the DFNB1-related deafness subgroup

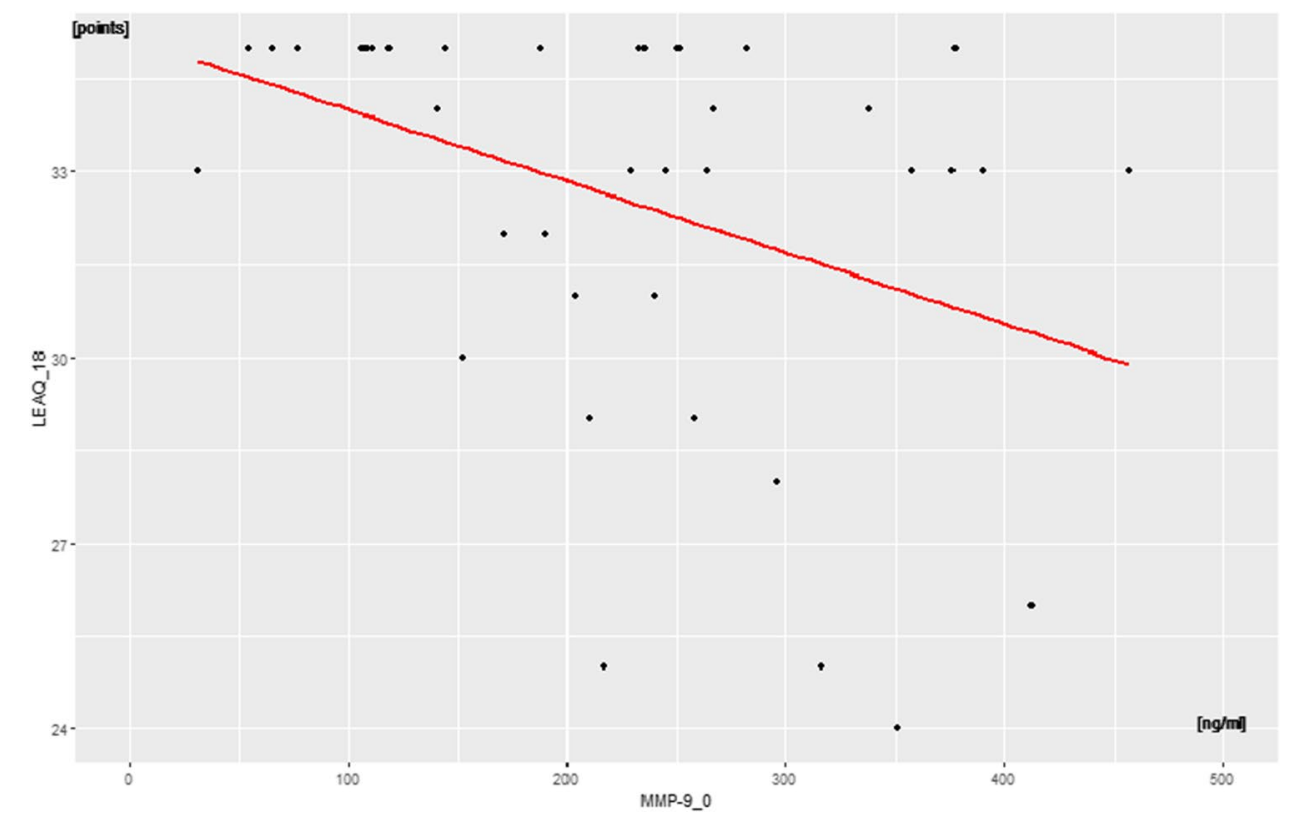


variation in the data. The $p$-values of the predictor variables and their associated impact on global outcome scores are shown in Table 2. In a similar way, for the same subgroup we built a multiple regression model using the tested polymorphisms as predictors, and the model revealed that one significant predictor of auditory development was follow-up interval (data not shown).

To give a clinical interpretation of the impact of the significant predictor pro-BDNF_0/BDNF_0 ratio on auditory development, the regression coefficient shows that a decrease in the ratio of 20 (1:0.05) will, on average, result in an increase of LEAQ score of 1 point in an implanted child with DFNB1-related deafness.

Table 2 Summary of linear mixed-effect model for LEAQ score in the DFNB1-related deafness subgroup. Estimates show the impact of significant predictors (marked by asterisks). $R^{2}=0.72$. SE, Standard Error

\begin{tabular}{llc}
\hline Predictors & $\begin{array}{l}\text { Dependent variable: } \\
\text { LEAQ, (SE) }\end{array}$ & $p$-value \\
\hline Follow-up interval (months) & $1.465^{\text {**** }}(0.086)$ & $<0.001$ \\
Sex & $0.863(1.301)$ & 0.508 \\
BDNF_0 & $0.245(0.348)$ & 0.483 \\
MMP9_0 & $-0.008(0.007)$ & 0.256 \\
Ratio pro-BDNF_0/BDNF_0 & $-0.049^{*}(0.024)$ & $<0.05$ \\
Age at CI activation & $0.008(0.006)$ & 0.183 \\
Constant & $7.385^{*}(2.936)$ & $<0.05$ \\
Observations & 120 & \\
Log likelihood & -411.014 & \\
Akaike info criterion & 840.028 & \\
Bayesian info criterion & 865.115 & \\
\hline
\end{tabular}

Analyses in Subgroups: DFNB1-Related Deafness and $\mathrm{Cl}$ Activation Before and After 1 Year

In none of the two DFNB1-related subgroups $(\mathrm{CI}<1$ or $\mathrm{CI}>1 \mathrm{y}$. o.) did we find any significant association between the analyzed $M M P 9$ and $B D N F$ genetic variants and LEAQ score at any of the tested follow-up intervals (data not shown).

In the subgroup with DFNB1-related deafness and CI activation after 1 year, hereafter referred to as older, no correlation between MMP-9_0 and LEAQ_0 was found, a positive correlation between BDNF_0 and LEAQ_0 score $(\mathrm{p}=0.03$, Rho $=0.4)$ and a negative correlation between pro-BDNF_0/BDNF_0 ratio and LEAQ_0 score $(p=0.01$, Rho $=-0.5)$ were found. Testing between MMP-9_0, BDNF_0, and pro-BDNF_0/BDNF_0 ratio with LEAQ_8 did not show any correlation. For LEAQ_18, it showed a moderate negative correlation between MMP-9_0 and LEAQ_18 score $(p=0.01$, rho $=-0.5)($ Fig. 3$)$ and no correlation between BDNF_0 and pro-BDNF_0/BDNF_0 and LEAQ_18.

Similar analyses performed in the DFNB1-related deafness and CI activation up to 1 year subgroup, hereafter referred to as younger, did not reach statistical significance.

For both younger and older subgroups, we built a linear mixed models on a set of 54 and 66 observations, respectively, with the tested polymorphisms as predictors. The model built for the older subgroup revealed that a significant predictor of auditory development outcome (LEAQ score), apart from the follow-up interval, is rs3918242 of MMP9 (Table 3). The regression coefficients show that an average patient who is a carrier of a C/C variant of rs3918242 of MMP9 will score, on average, 6.49 points higher at any
Fig. 3 Correlation between MMP-9_0 and auditory development measurements at 18 months after $\mathrm{CI}$ activation (LEAQ_18) in the subgroup with DFNB1-related deafness and $\mathrm{CI}$ activation after 1 year old

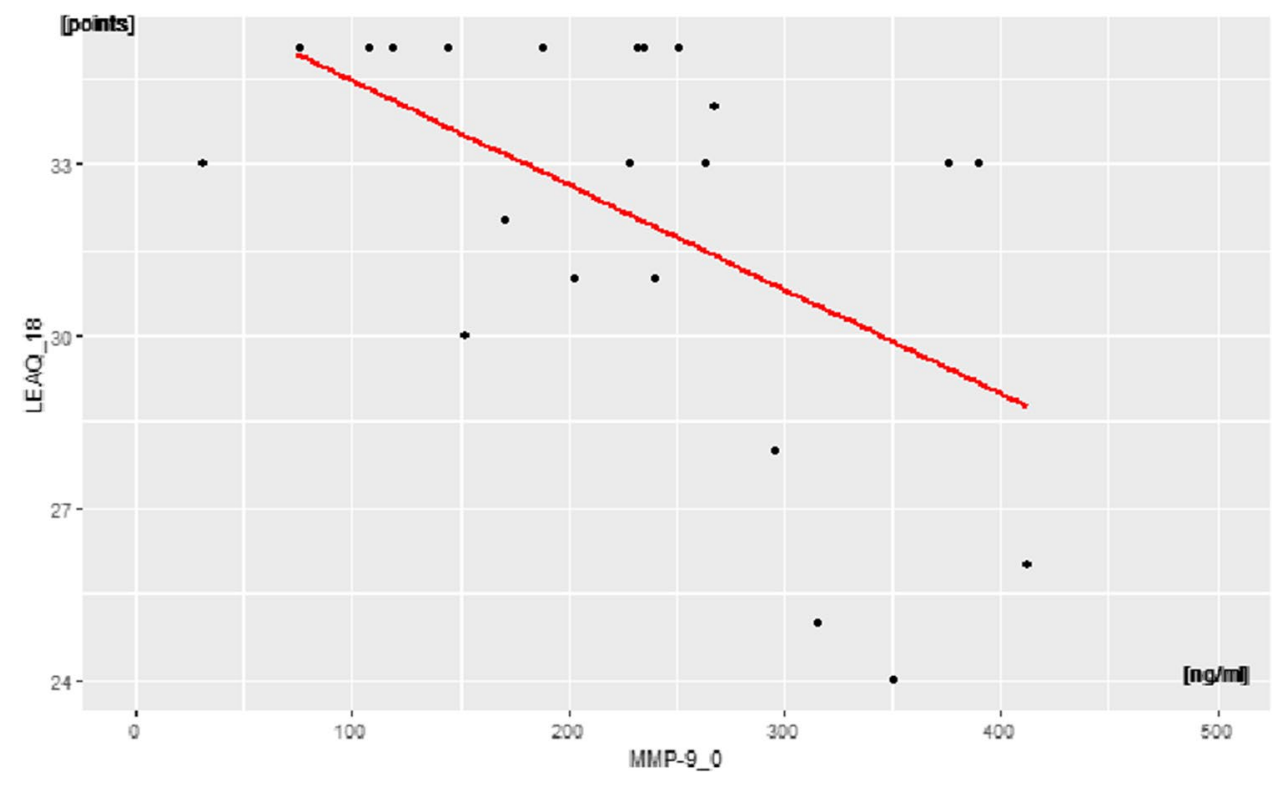


Table 3 Summary of linear mixed-effect model for LEAQ score in the subgroup with DFNB1-related deafness and CI activation after 1 year. Estimates show the impact of significant predictors (marked by asterisks). $R^{2}=-0.7$. SE, standard error

\begin{tabular}{lll}
\hline Predictors & $\begin{array}{l}\text { Dependent variable: } \\
\text { LEAQ, (SE) }\end{array}$ & $p$-value \\
\hline Follow-up interval (months) & $1.346^{* * * *}(0.121)$ & $<0.001$ \\
Sex & $0.231(2.100)$ & 0.913 \\
$B D N F$ rs6265 & $1.931(2.330)$ & 0.410 \\
$M M P 9$ rs2234681 =<20, $\geq 20$ & $5.390(5.746)$ & 0.352 \\
$M M P 9$ rs2234681= $\geq 20, \geq 20$ & $-1.271(3.684)$ & 0.731 \\
$M M P 9$ rs20544 & $-8.156(5.286)$ & 0.128 \\
$M M P 9$ rs3918242 & $-6.494(2.830)^{*}$ & $<0.05$ \\
Age at CI activation & $-0.001(0.010)$ & 0.929 \\
Constant & $13.209^{*}(5.963)$ & $<0.05$ \\
Observations & 66 & \\
Log likelihood & -212.487 & \\
Akaike info criterion & 446.974 & \\
Bayesian info criterion & 471.060 & \\
\hline
\end{tabular}

interval than a carrier of a $\mathrm{C} / \mathrm{T}$ variant. The $R^{2}$ for the model was 0.7 . The $p$-values of the predictor variables and their associated impact on global outcome scores are shown in Table 3. For the younger group, the model with tested polymorphisms as predictors revealed that the only significant predictor is the follow-up interval (data not shown). On the same sets of observations, we built multiple regression models for both subgroups, using inclusion of plasma levels of analyzed proteins (measured at CI activation) as predictors. The models did not reveal statistical significance for any of the predictors, apart from follow-up interval (data not shown).

We have determined relations between mean values of plasma levels of the tested proteins and genetic variants. We did not find any statistically significant differences either in the study group or in the DFNB1-related deafness subgroup.

\section{Discussion}

The present report seems to be the first to identify molecular and genetic biomarkers of neuronal plasticity after restoration of an absent sensory function in humans. The study has investigated possible associations between functional variants of the $M M P 9$ and $B D N F$ genes (and their products in plasma) and auditory development in congenitally deaf children after cochlear implantation. Our main findings can be summarized as follows. (i) Plasma level of MMP-9 protein measured at cochlear implantation in congenitally deaf children is significantly correlated with auditory development measurements (LEAQ score) at 18 months after the device activation. (ii) In the subgroup with DFNB1-related deafness, functional $M M P 9$ variant rs3918242 significantly impacts auditory development measured at the $18^{\text {th }}$ month after the device activation; it is also a significant predictor of overall LEAQ score in the subgroup with DFNB1-related deafness and activation after at the 1 year. (iii) The pro$\mathrm{BDNF} / \mathrm{BDNF}$ ratio measured at cochlear implantation is a significant predictor of auditory development (LEAQ score) as measured in the subgroup with DFNB1-related deafness.

For this prospective cohort study, we enrolled children diagnosed with bilateral congenital deafness without any comorbidities (and with noncontributory medical and pregnancy history). Patients were implanted with the same type of device, by the same experienced surgeon, and had their speech processor activated before second birthday; they also received the same rehabilitation program and their auditory development was observed for 18 months after CI activation. The literature already indicates that etiological homogeneity, such as mutations in the DFNB1 locus, has a predictive value for cochlear implantation outcome [6, 7, 10-12]. Following this lead, our analyses focused on the subgroup of children with DFNB1-related deafness, which was further divided into patients with CI activated before and after 1 year of life.

\section{Functional Variant rs3918242 of the MMP9 Gene and Auditory Development}

Out of the tested genetic variants of $M M P 9$ and $B D N F$, only rs3918242 $M M P 9$ showed significant association with auditory development in the subgroup with DFNB1-related deafness. At the $18^{\text {th }}$ month after $\mathrm{CI}$ activation, carriers of $\mathrm{C} / \mathrm{C}$ genotype scored, on average, 2.6 points higher than carriers of the C/T genotype (Table 1). This result is in line with results of our previous retrospective study, which reported the contribution of this polymorphism to LEAQ score over a 24-month follow-up in a cohort of 100 children with DFNB1-related deafness [50]. In the retrospective study, carriers of the $\mathrm{C} / \mathrm{C}$ genotype scored higher than carriers of the $\mathrm{C} / \mathrm{T}$ genotype, although the differences between their mean LEAQ scores did not reach significance. In the current analysis, we found statistically significant differences between mean LEAQ scores reached by the $\mathrm{C} / \mathrm{C}$ and $\mathrm{C} / \mathrm{T}$ genotype carriers at 18 -month follow-up. Since there is no literature on the molecular regulation of neuroplasticity after deafness treatment, our results of testing associations of $M M P 9$ polymorphisms need to be read in the context of published data on how these polymorphisms behave in other clinical conditions involving neuroplasticity. We observed a cohort of CI children, who, after activation of the CI and in response to stimulation delivered by the device, underwent a process of dynamic remodeling of cortical neuronal connections. The role of rs3918242 of MMP9 in neuronal plasticity has only been studied so far in the context of 
aberrant plasticity, e.g., in schizophrenia or addictions [28, $49,51-53]$. Of note, several groups have reported inconsistent data in case-control studies of rs3918242 of MMP9 involvement in the clinical picture of these diseases. For example, Rybakowski et al. [28] reported that the C/C genotype of rs3918242 of $M M P 9$ was implicated in schizophrenia susceptibility, but this finding has not been reproduced in other schizophrenia studies [51, 52]. However, a role for this polymorphism in schizophrenia has been confirmed in modifying the relationship between clinical severity and certain environmental risk factors [19]. Additionally, in an ethanol addiction study reported by Samochowiec et al. [53], the authors showed that the $\mathrm{C} / \mathrm{C}$ genotype was more frequent in the families of alcoholics than in controls.

In our material, the impact of rs3918242 of MMP9 on auditory development, among other genetic and clinical factors, was seen in a multiple regression model built around the older subgroup. The model indicated the significant effect of rs3918242 of MMP9 on overall LEAQ score at follow-up (Table 3). For the average carrier of the $\mathrm{C} / \mathrm{C}$ genotype, the average estimated LEAQ score was found to be higher by 6.49 points than for a carrier of the C/T genotype, a difference which can be converted into 7.7 months of delay in auditory development after cochlear implantation [38]. Clearly, the effect of follow-up interval has the highest impact on LEAQ score as predictor in the model, since it reflects the duration of CI use and the biological age of the implanted child, so it will inevitably rise from one follow-up interval to the next. It has already been well documented that the child's age when auditory development is measured is the strongest factor in shaping the outcome [2].

\section{Plasma Level of MMP-9 Protein Measured at Cochlear Implantation}

In our material, plasma samples taken at cochlear implantation from carriers of less transcriptionally active $\mathrm{C} / \mathrm{C}$ genotype of rs3918242 of MMP9 showed lower levels of MMP-9 protein than samples from carriers of the more active $\mathrm{C} / \mathrm{T}$ genotype. This pattern was repeated in the DFNB1-related deafness subgroup, although these differences did not reach statistical significance ( $p=0.07$ and $p=0.06$, respectively) (Supplementary Tables 2 and 3). Further analyses showed a significant negative correlation between the plasma level of MMP-9 protein measured at cochlear implantation with LEAQ score measured at the end-point observation (LEAQ_18) for (i) the whole study group; (ii) the DFNB1related deafness subgroup; and (iii) the subgroup with DFNB1-related deafness and CI activation after 1 year of life $(p=0.04$, rho $=-0.25 ; p=0.005$, rho $=-0.4 ;$ and $p=0.01$, rho $=0.5$, respectively) (Figs. 1-3). These correlations indicate that a deaf child, who at cochlear implantation has a lower MMP-9 protein plasma level is predisposed to better auditory outcome after 18 months of speech and language rehabilitation. Only for the youngest group do we not see this trend.

Rs3918242 of MMP9, being a result of functional C > T transition in the gene promoter region, exerts a critical effect on transcriptional activity [51, 52]. This finding may be interpreted in line with data reported in our retrospective study, in which we did not find a significant association between rs3918242 of MMP9 and auditory development for children implanted before their first birthday, contrary to children implanted after their first birthday [50]. However, this finding needs to be regarded with caution, since differences in MMP-9 protein plasma levels for carriers of the C/C and $\mathrm{C} / \mathrm{T}$ genotypes did not reach significance. On the other hand, this age-dependent difference also supports our other conclusion that there may be differences in molecular mechanisms underlying cognitive processing in very young children (implanted before and after their first birthday). Data reported in this paper suggest that activated pathways may not involve MMP-9 if the delivery of sensory stimuli takes place before the first year of life. Plasma levels of MMP9_0 and BDNF_0 proteins were not significantly affected by the other functional variants mentioned (Supplementary Tables 2 and 3).

To date, we have not found any published protein data for plasma samples taken from a homogenous cohort of congenitally sensory-deprived patients. For this reason and to gain more insight into the molecular background of neural plasticity, we need to compare our results with reports from studies involving other physiological and pathological conditions. The role of MMP-9 in neuronal plasticity has already been well-studied, and its influence on this process has been documented in memory and learning and various pathological neuropsychiatric conditions, such as schizophrenia, addiction, or epilepsy [17, 18, 51, 54]. A body of literature describes, for rodents, an important role for the MMP-9 protein in the critical plasticity period [20]. This molecule is mainly involved in the active structural and functional reorganization of excitatory synapses and dendritic spines and is subject to multifactorial regulation at several levels, such as gene expression, mRNA stability, and localization (including translocation toward dendrites and synapses), protein production and release, and enzymatic activity [17, 18, 20, 22, 49, 55]. Expression studies of $M M P 9$ in auditory pathway, apart from the cortex, are sparse and limited only to animal data. The expression of $M M P 9$ has been detected in the organ of Corti, specifically in the pillar cells and inner and outer hair cells, and in the spiral ganglion cells [56-59]. Studies on MMP9 knockout mice have shown that the MMP-9 protein is critical for appetitive learning and memory formation [60]. Research on human schizophrenia patients shows that elevated MMP-9 protein levels are significantly correlated with cognitive decline, particularly in 
terms of language, fluency, and verbal and general memory [51, 54, 61, 62].

Our data do not show the actual, temporal relation between MMP-9 protein levels in plasma and the phenotype. Changes in MMP-9 plasma levels may influence the phenotype. This has been indirectly observed in animal models, as well as in clinical studies on Fragile X syndrome (FXS) children treated with the MMP-9 inhibitor minocycline [63-65]. FXS is due to a lack of FMRP (Fragile X Mental Retardation Protein), which is associated with alterations in the expression of MMP-9, and in animal models there are elevated levels of the protein in the hippocampus, which is lowered after minocycline administration. Early treatment (before the fourth week of life) with minocycline promotes the maturation of dendritic spines in vivo and in vitro and relieves anxiety and improves cognition [63]. In human trials, authors report significant decreases in typical symptoms of FXS after minocycline administration (attention deficits, mood disorders, hyperactivity, cognition, and language fluency) [64].

\section{Ratio of pro-BDNF/BDNF Plasma Levels Measured at Cochlear Implantation}

In light of our current state of knowledge about the molecular background of neural plasticity and the role of BDNF in these processes, the apparent lack of involvement of BDNF in the results presented here is surprising [29, 30, 66, 67]. We have found no significance of $B D N F$ polymorphisms, nor a role for the protein in auditory development, and no correlation between pro-BDNF_0/BDNF_0 ratio and LEAQ scores. Nevertheless, a multiple regression model based on data from the DFNB1-related deafness subgroup over 18 months of observation has shown both follow-up interval, and pro-BDNF_0/BDNF_0 ratio play a significant role in the auditory development of the implanted children (Table 2). Of course, in the model we find that a follow-up interval, as in a regression model built using gene polymorphisms as predictors, is the most significant predictor. BDNF is a large molecule that is cleaved by proteases from pro-BDNF into the mature form and exerts a range of neurotrophic effects on neurons [36, 67]. Animal studies demonstrate that MMP-9 may also play a role in converting the pro-form of BDNF into its mature form [35]. Interestingly, recent accumulating evidence suggests that pro-BDNF and BDNF may have opposite effects on neuronal plasticity [33, 36, 67, 68]. Abnormalities in conversion of pro-BDNF to BDNF have already been postulated as helping to explain certain neuropathological processes underlying various brain disorders like bipolar depression or epilepsy [33, 35]. After applying the linear mixed-effect model methodology to our cohort of children with DFNB1-related deafness, we have found a progressive decrease in pro-BDNF_0/BDNF_0 ratio. Acting over the long neurodevelopmental process that occurs following a period of sensory deprivation, a change in ratio of 20 predisposes an implanted child to score 1 point higher in LEAQ (Table 2). However, we see a very wide range in the ratio of pro-BDNF_0/BDNF_0 in DFNB-1 related deafness subgroup (0.2 to 161.5, SD 29.4), so it is clear that the relation reflects a highly dynamic process.

\section{Perspective}

Our data should be interpreted with caution. However, they do provide an indication of children's capacity for successful speech and language rehabilitation after cochlear implantation. We have not isolated a biomarker of children who risk failure in speech and language rehabilitation, but we were able to point to a biochemical marker of good performers. Further research on larger sample size data and multicenter studies are needed to confirm this finding. However, broadening the preimplant diagnostic panel of commercially available ELISA (enzyme-linked immunosorbent assay) tests for MMP-9 plasma level would add considerable value and is easy to implement into clinical practice.

\section{Limitations}

This is the first attempt to shed light on the molecular machinery of neuroplasticity after cochlear implantation in congenital deafness treatment, and as such it has many limitations and should be subject to wide-ranging critique. An undeniable weakness of this study is the measurement tool for assessing language development-the LEAQ and, in particular, its subjective character. Moreover, the effect of environmental factors, like parental/maternal educational status, the parents' motivation to support the child through rehabilitation and the degree of speech training patients receive in it, is very difficult to control during such a study. We have followed the children only up to the $18^{\text {th }}$ month after CI activation; further longitudinal observation would add valuable detail on linguistic competency. Another factor limiting the group homogeneity, but which was out of our control, is the degree of cross-modal cortical reorganization before cochlear implantation. Despite a relatively short period of auditory deprivation in our patients, reorganization could have already taken place and could have affected the outcome $[16,69]$. We used only a relatively small sample size, comprising subjects from the Polish population. Largescale, multicenter studies incorporating subjects of different ethnicities are needed to see whether these results may be 
repeated more universally. Finally, both tested proteins are also involved in numerous other biological processes in the human body, which are not connected with neuronal plasticity, and so the relations between protein plasma level and phenotype seen in our material may not be repeatable in cases where there are other health problems.

Supplementary Information The online version contains supplementary material available at https://doi.org/10.1007/s12035-022-02732-7.

Acknowledgements The authors would like to thank to all participants and their parents or caregivers for cooperation in this study and the Board of Directors of the Institute of Physiology and Pathology of Hearing in Warsaw for their support.

Authors' contributions MM and LK performed conceptualization; MM done data curation, software, writing original draft and funding acquisition; MM and DO contributed to formal analysis, visualization and investigation; MM, DO, MO, ER were involved in methodology; HS and MM contributed to resources; LK and HS supervised the study; MM, DO, and PHS validated the study; LK, DO, MO, MM done writing review and editing.

Funding This paper represents independent research funded by the National Centre of Science, grant nr UMO 2014/13/D/NZ5/03337.

ER and LK have been supported by the BRAINCITY MAB/2018/10. The "Center of Excellence for Neural Plasticity and Brain Disorders: BRAINCITY" project is carried out within the International Research Agendas Programme of the Foundation for Polish Science co-financed by the European Union under the European Regional Development Fund.

Data Availability The datasets analyzed during this study are accessible on reasonable request.

\section{Declarations}

Ethics Approval The study was designed and conducted according to the Declaration of Helsinki. It was reviewed and approved by the Bioethics Committee of the Institute of Physiology and Pathology of Hearing (no. IFPS:KB/13/2015).

Consent to Participate and for Publication Parents or caregivers of all participants gave written informed consent.

Conflict of Interest The authors declare that there is no conflict of interests.

Open Access This article is licensed under a Creative Commons Attribution 4.0 International License, which permits use, sharing, adaptation, distribution and reproduction in any medium or format, as long as you give appropriate credit to the original author(s) and the source, provide a link to the Creative Commons licence, and indicate if changes were made. The images or other third party material in this article are included in the article's Creative Commons licence, unless indicated otherwise in a credit line to the material. If material is not included in the article's Creative Commons licence and your intended use is not permitted by statutory regulation or exceeds the permitted use, you will need to obtain permission directly from the copyright holder. To view a copy of this licence, visit http://creativecommons.org/licenses/by/4.0/.

\section{References}

1. Kral A, Kronenberger WG, Pisoni DB, O’Donoghue GM (2016) Neurocognitive factors in sensory restoration of early deafness: a connectome model. Lancet Neurolol 15(6):610-621. https://doi. org/10.1016/S1474-4422(16)00034-X

2. Niparko et al. (2010) Spoken language development in children following cochlear implantation JAMA. 303(15):14981506. https://doi.org/10.1001/jama.2010.451

3. De Raeve L (2010) A longitudinal study on auditory perception and speech intelligibility in deaf children implanted younger than 18 months in comparison to those implanted at later ages. Otol Neurotol 31(8):261-267. https://doi.org/10.1097/MAO.0b013 e3181f1cde3

4. Fallon JB, Irvine DRF, Shepherd RK (2009) Neural prostheses and brain plasticity. J Neural Eng 6(6):065008. https://doi.org/10. 1088/1741-2560/6/6/065008

5. Houston DM, Stewart J, Moberly A, Hollich G, Miyamoto RT (2012) Word learning in deaf children with cochlear implants: effects of early auditory experience. Dev Sci 15:448-461. https:// doi.org/10.1111/j.1467-7687.2012.01140.x

6. Oziębło D, Obrycka A, Lorens A, Skarżyński H, Ołdak M (2020) Cochlear implantation outcome in children with DFNB1 locus pathogenic variants. J Clin Med 9(1):228. https://doi.org/10.3390/ jcm9010228

7. Abdurehim Y, Lehmann A, Zeitouni AG (2017) Predictive value of GJB2 mutation status for hearing outcomes of pediatric cochlear implantation. Otolaryngol Head Neck Surg 157(1):16-24. https://doi.org/10.1177/0194599817697054

8. Shearer AE, Eppsteiner RW, Frees K, Tejani V, Sloan-Heggen CM, Brown C, Abbas P, Dunn C, et al. (2017) Genetic variants in the peripheral auditory system significantly affect adult cochlear implant performance. Hear Res 348:138-142. https://doi.org/10. 1016/j.heares.2017.02.008

9. Park JH, Kim AR, Han JH, Kim SD, Kim SH, Koo J-W, Oh SH, Choi BY (2017) Outcome of cochlear implantation in prelingually deafened children according to molecular genetic etiology. Ear Hear 38(5):e316-e324. https://doi.org/10.1097/AUD.0000000000 000437

10. Reinert J, Honegger F, Gurtler N (2010) High homogeneity in auditory outcome of pediatric CI-patients with mutations in Gap-Junction-Protein Beta2. Intl J Pediatr Otorhinolaryngol 74(7):791-795. https://doi.org/10.1016/j.ijporl.2010.04.002

11. Eppsteiner RW, Shearer AE, Hilderbrand MS, DeLuca AP, Haihong J, Dunn CC, Black-Ziegelbein EA, et al. (2012) Prediction of cochlear implant performance by genetic mutation: the spiral ganglion hypothesis. Hear Res. 292(1-2):51-58. https:// doi.org/10.1016/j.heares.2012.08.007

12. Angeli SI, Suarez H, Lopez H, Balkany T, Liu XZ (2011) Influence on DFNB1 status on expressive language in deaf children with cochlear implants. Otol Neurotol 32:1437-1443. https://doi. org/10.1097/mao.0b013e31823387f9

13. Smith RJH, Jones MKN (1998). Nonsyndromic Hearing Loss and Deafness, DFNB1. Sep 28 [Updated 2016 Aug 18]. In: Adam MP, Ardinger HH, Pagon RA, et al., editors. GeneReviews ${ }^{\circledR}$ [Internet]. Seattle (WA): University of Washington, Seattle; 1993-2021. Available from: https://www.ncbi.nlm.nih.gov/books/ NBK1272/

14. Chen J, Chen J, Zhu Y, Liang C, Zhao HB (2014) Deafness induced by Connexin 26 (GJB2) deficiency is not determined by endocochlear potential (EP) reduction but is associated with cochlear developmental disorders. Biochem Biophys Res Commun 448:28-32. https://doi.org/10.1016/j.bbrc.2014.04.016

15. Kikuchi T, Adams JC, Miyabe Y, So E, Kobayashi T (2000) Potassium ion recycling pathway via gap junction systems in the 
mammalian cochlea and its interruption in hereditary nonsyndromic deafness. Med Electron Microsc 33(2):51-56. https://doi.org/ 10.1007/s007950070001

16. Lee H-J, Giraud A-L, Kang E, Oh S-H, Kang H, Kim C-S, Lee D-S (2007) Cortical activity at rest predicts cochlear implantation outcome. Cereb Cortex 17:909-917. https://doi.org/10.1093/ cercor/bh1001

17. Beroun A, Mitra S, Michaluk P, Pijet B, Stefaniuk M, Kaczmarek L (2019) MMPs in learning and memory and neuropsychiatric disorders. Cell Mol Life Sci 76(16):3207-3228. https://doi.org/ 10.1007/s00018-019-03180-8

18. Vafadari B, Salamian A, Kaczmarek L (2016) MMP-9 in translation: from molecule to brain physiology, pathology, and therapy. J Neurochem 139(Suppl 2):91-114. https://doi.org/10.1111/jnc. 13415

19. McGregor N, Thompson N, O'Connell KS, Emsley R, van der Merwe L, Warnich L (2018) Modification of the association between antipsychotic treatment response and childhood adversity by MMP9 gene and its variants in a first-episode schizophrenia cohort. Psychiatry Res 262:141-148. https://doi.org/10.1016/j. psychres.2018.01.044

20. Reinhard SM, Razak K, Ethell I (2015) A delicate balance: role of MMP9 in brain development and pathophysiology of neurodevelopmental disorders. Front Cell Neurosci 9:280. https://doi.org/ 10.3389/fncel.2015.00280

21. Rivera S, Khrestchaitsky M, Kaczmarek L, Rosenberg G, Jaworski DM (2010) Metzincin proteases and their inhibitors: foes and friends in nervous system physiology? J Neurosci 30(46):1533715357. https://doi.org/10.1523/jneurosci.3467-10.2010

22. Vandooren J, Van den Steen PE, Opdenakker G (2013) Biochemistry and molecular biology of gelatinase $\mathrm{B}$ or matrix metalloproteinase-9 (MMP-9): the next decade. Crit Rev Biochem Mol Biol 48(3):222-272. https://doi.org/10.3109/10409238.2013.770819

23. Ethel IM, Ethel DW (2007) Matrix metalloproteinases in brain development and remodeling: synaptic functions and targets. J Neurosci Res 85(13):2813-2823. https://doi.org/10.1002/jnr. 21273

24. Nagy V, Bozdagy O, Matynia A, Balcerzak M, Okulski P, Dzwonek J, Costa RM, Silva AJ, et al. (2006) Matrix metalloproteinase-9 is required for hippocampal late-phase long-term potentiation and memory. J Neurosci 26(7):1923-1934. https:// doi.org/10.1523/jneurosci.4359-05.2006

25. Nagy V, Bozdagy O, Huntley WH (2007) The extracellular protease matrix metalloproteinase- 9 is required by inhibitory avoidance learning and required for long term memory. Learn Mem 14(10):655-664. https://doi.org/10.1101/lm.678307

26. Bozdagi O, Nagy V, Kwei KT, Huntley GW (2007) In vivo roles for matrix metalloproteinase-9 in mature hippocampal synaptic physiology and plasticity. J Neurophysiol 98(1):334-344. https:// doi.org/10.1152/jn.00202.2007

27. Okulski P, Jay TM, Jaworski J, Duniec K, Dzwonek K, Dzwonek J, Konopacki FA, Wilczynski GM, et al.(2007) TIMP-1 abolishes MMP-9-dependent long-lasting long-term potentiation in the prefrontal cortex. Biol Psychiatry 62(4):359-362. https://doi.org/10. 1016/j.biopsych.2006.09.012

28. Rybakowski JK, Skibińska M, Kapelski P, Kaczmarek L, Hauser J (2009) Functional polymorphism of the matrix metalloproteinase-9 (MMP-9) gene in schizophrenia. Schizophr Res 109(13):90-93. https://doi.org/10.1016/j.schres.2009.02.005

29. Bekinschtein P, Cammarota M, Medina JH (2014) BDNF and memory processing. Neuropharmacology 76:677-683. https://doi. org/10.1016/j.neuropharm.2013.04.024

30. Hariri AR, Goldberg TE, Mattay VS, Kolachana BS, Callicott JH, Egan MF, Weinberger DR (2003) BDNF val66met polymorphism affects human memory-related hippocampal activity and predicts memory performance. J Neurosci 23(17):6690-6694. https://doi. org/10.1523/jneurosci.23-17-06690.2003

31. Leal G, Comprido D, Duarte CB (2014) BDNF-induced local protein synthesis and synaptic plasticity. Neuropharmacology 76:639-656. https://doi.org/10.1016/j.neuropharm.2013.04.005

32. Zagrebelsky M, Korte M (2014) Form follows function: BDNF and its involvement in sculpting the function and structure of synapses. Neuropharmacology 76:628-638. https://doi.org/10.1016/j. neuropharm.2013.05.029

33. Sodersten K, Palsson E, Ishima T, Funa K, Landen M, Hashimoto $\mathrm{K}$, Agren H (2014) Abnormality in serum levels of mature BDNF and its precursor proBDNF in mood stabilized patients with bipolar disorder: a study of two independent cohorts. J Affect Disord 160:1-9. https://doi.org/10.1016/j.jad.2014.01.009

34. Siuda J, Patalong-Ogiewa M, Żmuda W, Targosz-Gajniak M, Niewiadomska E, Matuszek I, Jędrzejowska-Szypułka H, LewinKowalik J, et al. (2017) Cognitive impairment and BDNF serum levels. Neurol Neurochir Pol 51(1):24-32. https://doi.org/10. 1016/j.pjnns.2016.10.001

35. Mizoguchi H, Nakade J, Tachibana M, Ibi D, Someya E, Koike H, Kamei H, Nabeshima T, et al. (2011) Matrix metalloproteinase-9 contributes to kindled seizure development in pentylenetetrazole-treated mice by converting pro-BDNF to mature BDNF in the hippocampus. J Neurosci 31(36):12963-12971. https://doi.org/10.1523/jneurosci.3118-11.2011

36. Hashimoto K (2010) Brain-derived neurotrophic factor as a biomarker for mood disorders: an historical overview and future directions. Psychiatry Clin Neurosci 64(4):341-357. https://doi. org/10.1111/j.1440-1819.2010.02113.x

37. Weichbold V, Tsiakpini L, Coninx F, D'Haese P (2005) Development of a parent questionnaire for assessment of auditory behaviour of infants up to two years of age. Laryngorhinootologie 84(5):328-334. https://doi.org/10.1055/s-2004-826232

38. Obrycka A, Padilla GJ, P., Pankowska A., Lorens A., Skarżynski H. (2009) Production and evaluation of a Polish version of the LittlEars questionnaire for the assessment of auditory development in infants. Int J Pediatr Otorhinolaryngol 73(7):10351042. https://doi.org/10.1016/j.ijporl.2009.04.010

39. Obrycka A, Lorens A, Padilla JL, Piotrowska A, Skarżyński H (2017) Validation of the LittlEARS Auditory Questionnaire in cochlear implanted infants and toddlers. Int J Pediatr Otorhinolaryngol 93:107-116. https://doi.org/10.1016/j.ijporl.2016. 12.024

40. Coninx F, Weichbold V, Tsiakpini L, Autrique E, Bescond G, Tamas L, Compernol A, Georgescu M, Koroleva I, Le ManerIdrissi G, Liang W, Madell J, Miić B, Obrycka A, Pankowska A, Pascu A, Popescu R, Radulescu L, Reuhamaki T, Rouev P, Kabatova Z, Spitzer J, Thodi Ch, Varzic F, Vischer M, Wang L, Zavala JS, Brachmaier J (2009) Validation of the LittlEARS Auditory Questionnaire in children with normal hearing. Int J Pediatr Otorhinolaryngol 73(12):1761-1768. https://doi.org/10. 1016/j.ijporl.2009.09.036

41. Geal-Dor M, Jbarah R, Meilijson S, Adelman C, Levi H (2011) The Hebrew and the Arabic version of the LittlEARS Auditory Questionnaire for the assessment of auditory development: Results in normal hearing children and children with cochlear implants. Int J Pediatr Otorhinolaryngol 75(10):1327-1332. https://doi.org/10.1016/j.ijporl.2011.07.030

42. Wanga L, Sun X, Liang W, Chen J, Zheng W (2013) Validation of the Mandarin version of the LittlEARS Auditory Questionnaire. Int J Pediatr Otorhinolaryngol 77(8):1350-1354. https:// doi.org/10.1016/j.ijporl.2013.05.033

43. García NA, S., Padilla García J. L., SainzQuevedo M., (2016) Production and evaluation of a Spanish version of the LittlEARS Auditory Questionnaire for the assessment of auditory 
development in children. Int J Pediatr Otorhinolaryngol 83:99103. https://doi.org/10.1016/j.ijporl.2016.01.021

44. St JP, L., Zhang X. C., Hart B. K., Lamlum H., Webster M. W., Steed D., L., Henney A., M., Ferrell R. E. (1995) Characterization of a dinucleotide repeat in the $92 \mathrm{kDa}$ type IV collagenase gene (CLG4B), localization of CLG4B to chromosome 20 and the role of CLG4B in aortic aneurysmal disease. Ann Hum Genet 59(Pt 1):17-24. https://doi.org/10.1111/j.1469-1809. 1995.tb01602.x

45. Shimajiri S, Arima N, Tanimoto A, Murata Y, Hamada T, Wang KY, Sasaguri Y (1999) Shortened microsatellite d(CA)21 sequence down-regulates promoter activity of matrix metalloproteinase 9 gene. FEBS Lett 455(1-2):70-74. https://doi.org/ 10.1016/s0014-5793(99)00863-7

46. Huang T-S, Lee C-C, Chang A-C, Shankung L, Chao C-C, Jou Y-S, Chu Y-W, Wu C-W, et al. (2003) Shortening of microsatellite deoxy(CA) repeats involved in GL331-induced down-regulation of matrix metalloproteinase- 9 gene expression. Biochem Biophys Res Commun 300(4):901-907. https://doi.org/10.1016/s0006$291 \times(02) 02962-5$

47. Fiotti N, Moretti ME, Bussani R, Altamura N, Zamolo F, Gerloni R, Ukovich L, Ober E, et al. (2011) Features of vulnerable plaques and clinical outcome of UA/NSTEMI: Relationship with matrix metalloproteinase functional polymorphisms. Atherosclerosis 215(1):153-159. https://doi.org/10.1016/j.atherosclerosis.2010. 12.010

48. Hirakawa S, Lange E, Colicigno C, Freedman B, Rich S, Bowden D. Evaluation of genetic variation and association in the matrix metalloproteinase 9 (MMP9) gene in ESRD patients. Am J Kidney Dis 42:133-42. https://doi.org/10.1016/s0272-6386(03)00416-5

49. Lepeta K, Purzycka KJ, Pachulska-Wieczorek K, Mitjans M, Begemann M, Vafadari B, Bijata K, Adamiak RW, et al. (2017) A normal genetic variation modulates synaptic MMP-9 protein levels and the severity of schizophrenia symptoms. EMBO Mol Med 9(8):1100-1116. https://doi.org/10.15252/emmm.201707723

50. Matusiak M, Oziębło D, Obrycka A, Ołdak M, Kaczmarek L, Skarżyński P, Skarżyński H (2021) Functional polymorphism of MMP9 and BDNF as a potential biomarker of auditory plasticity in prelingual deafness treatment with cochlear implantation: a retrospective cohort analysis. Trends Hear 25:23312165211002140. https://doi.org/10.1177/23312165211002140

51. Ali FT, Abd El-Azeem EM, Hamed MA, Ali MAM, Abd AlKader NM, Hassan EA (2017) Redox dysregulation, immunoinflammatory alterations and genetic variants of BDNF and MMP-9 in schizophrenia: pathophysiological and phenotypic implications. Schizophr Res. 188:98-109. https://doi.org/10. 1016/j.schres.2017.01.016

52. Xia Q-R, Zhang C, Liang J, Xu Y-Y (2019) The association of functional polymorphism of matrix metalloproteinase-9 gene (rs3918242) with schizophrenia: a meta-analysis. Int J Psychiatry Clin Pract 23(3):207-214. https://doi.org/10.1080/13651501. 2019.1581895

53. Samochowiec A, Grzywacz A, Kaczmarek L, Bienkowski P, Samochowiec J, Mierzejewski P, Preuss UW, Grochans E, et al. (2010) Functional polymorphism of matrix metalloproteinase-9 (MMP-9) gene in alcohol dependence: family case control study. Brain Res 1327:103-106. https://doi.org/10.1016/j.brainres.2010. 02.072

54. Kudo N, Yamamori H, Ishima T, Nemoto K, Yasuda Y, Fujimoto M, Azechi H, Niitsu T, et al. (2020) Plasma levels of matrix metalloproteinase-9 (MMP-9) are associated with cognitive performance in patients with schizophrenia. Neuropsychopharmacol Rep 40(2):150-156. https://doi.org/10.1002/npr2.12098
55. Michaluk P, Wawrzyniak M, A lot P., Szczot M., Wyrembek P., Mercik K., Medvedev N., Wilczek E., et al. (2011) Influence of matrix metalloproteinase MMP-9 on dendritic spine morphology. J Cell Sci 124(Pt 19):3369-3380. https://doi.org/10.1242/ jes.090852

56. Setz C, Brand Y, Radojevic V, Hanusek C, Mullen PJ, Levano S, Listyo A, Bodmer D (2011) Matrix metalloproteinases 2 and 9 in the cochlea: expression and activity after aminoglycoside exposition. Neuroscience 181:28-39. https://doi.org/10.1016/j.neuro science. 2011.02.043

57. Sung M, Wei E, Chavez E, Jain N, Levano S, Binkert L, Ramseier A, Setz C, et al. (2014) Inhibition of MMP-2 but not MMP-9 influences inner ear spiral ganglion neurons in vitro. Cell Mol Neurobiol 34(7):1011-1021. https://doi.org/10.1007/ s10571-014-0077-2

58. Wu J, Han W, Chen X, Guo W, Liu K, Wang R, Zhang J, Sai N (2017) Matrix metalloproteinase- 2 and -9 contribute to functional integrity and noise-induced damage to the blood-labyrinth-barrier. Mol Med Rep 16(2):1731-1738. https://doi.org/10.3892/mmr. 2017.6784

59. Hu BH, Cai Q, Hu Z, Patel M, Bard J, Jamison J, Coling D (2012) Metalloproteinases and their associated genes contribute to the functional integrity and noise-induced damage in the cochlear sensory epithelium. J Neurosci 32(43):14927-14941. https://doi. org/10.1523/JNEUROSCI.1588-12.2012

60. Knapska E, Lioudyno V, Kiryk A, Mikosz M, Górkiewicz T, Michaluk P, Gawlak M, Chaturvedi M, et al. (2013) Reward learning requires activity of matrix metalloproteinase- 9 in the central amygdala. J Neurosci 33(36):14591-14600. https://doi.org/10. 1523/JNEUROSCI.5239-12.2013

61. Keshri N, Nandeesha H, Rajappa M, Menon V (2021) Matrix metalloproteinase-9 increases the risk of cognitive impairement in schizophrenia. Nord J Psychiatry 75(2):130-134. https://doi. org/10.1080/08039488.2020.1808901

62. Yamamori H, Hashimoro R, Ishima T, Kishi F, Yasuda Y, Ohi K, Fujimoto M, Umeda-Yanp S, et al. (2013) Plasma levels of matire brain-derived neurotrophic factor (BDNF) and matrix metalloproteinase-9 (MMP-9) in treatment-resistant schizophrenia treated with clozapine. Neurosci Lett 556:37-41. https://doi.org/ 10.1016/j.neulet.2013.09.059

63. Bilousova TV, Dansie L, Ngo M, Aye J, Charles JR, Ethell DW, Ethell IM (2009) Minocycline promotes dendritic spine maturation and improves behavioural performance in the fragile $\mathrm{X}$ mouse model. J Med Genet 46:94-102. https://doi.org/10.1136/jmg.2008. 061796

64. Leigh MJ, Nguyen DV, Mu Y, Winarni TI, Schneider A, Chechi T, Polussa J, Dpucet P, et al. (2013) A randomized double-blind, placebo-controlled trial of minocycline in children and adolescents with Fragile X Syndrome. J Dev Behav Pediatr 34(3):147-155. https://doi.org/10.1097/DBP.0b013e318287cd17

65. Schenider A, Leigh MJ, Adams P, Nanakul R, Chechi T, Olichney J, Hagerman R, Hessl D (2013) Electrocortical changes associated with minocycline treatment in fragile $\mathrm{X}$ syndrome. J Psychopharmacol 27(10):956-963. https://doi.org/10.1177/0269881113 494105

66. Brunoni AR, Lopes M, Fregni F (2008) A systematic review and meta-analysis of clinical studies on major depression and BDNF levels: implications for the role of neuroplasticity in depression. Int J Neuropsychopharmacol 11(8):1169-1180. https://doi.org/10. 1017/S1461145708009309

67. Yoshida T, Ishikawa M, Niitsu T, Nakazato M, Watanabe H, Shiraishi T, Shiina A, Hashimoto T, et al. (2012) Decreased serum level of mature Brain-Derived Neurotrophic Factor (BDNF), but 
not its precursor proBDNF, in patients with major depressive disorder. PLoS ONE 7(8):e42676. https://doi.org/10.1371/journal. pone.0042676

68. Yoshimura R, Kishi T, Hori H, Atake K, Katsuki A, NakanoUmene W, Ikenouchi-Sugita A, Uwata N, et al. (2014) Serum proBDNF/BDNF and response to fluvoxamine in drug naïve firstepisode major depressive disorder patients. Ann Gen Psychiatry 13:19. https://doi.org/10.1186/1744-859X-13-19
69. Glennon E, Svirsky MA, Froemke RC (2020) Auditory cortical plasticity in cochlear implant users. Curr Opin Neurobiol 60:108 114. https://doi.org/10.1016/j.conb.2019.11.003

Publisher's Note Springer Nature remains neutral with regard to jurisdictional claims in published maps and institutional affiliations. 